\title{
Breaking news for the fifth year of Internal and Emergency Medicine
}

\author{
Domenico Prisco
}

Published online: 27 January 2010

(C) SIMI 2010

\section{Dear Colleagues,}

With this first issue of 2010 IEM is entering its fifth year of publication, and this is the fourth issue I have the honor to sign as Editor-in-Chief.

As you can see, the Editorial Board has been renewed. Significant changes were introduced both in the composition and in the more general organization.

First of all, we introduced a new Board in addition to the existing Internal Medicine and Emergency Medicine ones. The reason of this reorganization is to take advantage of a wider panel of experts in a broader range of subdisciplines of Internal Medicine. The new Board deals with Clinical Evidence and Health Technology Assessment and will be chaired by the past Editor-in-Chief, Gian Franco Gensini. He will be supported by the Deputy Editor Lorenzo Moja and the joining members. I wish these colleagues success achievements in their new endeavor.

Significant changes have also been introduced in the composition of the Editorial Board of Emergency Medicine, with the introduction of new European and American members, and in that of Internal Medicine.

Finally, the International Advisory Board has been reintroduced and includes past and new collaborators of our journal.

I wish to thank the past President of the Italian Society of Internal Medicine (SIMI), Giuseppe Licata, the new President Francesco Violi, and all the members of past and new SIMI Council for providing me their support.

\section{Prisco $(\square)$}

Editor-in-Chief, Internal and Emergency Medicine,

Dipartimento di Area Critica Medico Chirurgica,

Università degli Studi di Firenze, Viale Morgagni 85,

50134 Florence, Italy

e-mail: priscod@aou-careggi.toscana.it
A special thank goes to the Co-Editor Peter Rosen for his continuous and precious job in leading the Emergency Section of the journal.

Good news from the Publisher!

Usage of IEM articles increased five times from 2007 to 2008. Moreover, in the period January-September, the 2009 growth ratio of full-text downloads reached $27 \%$.

PubMed linkouts number represents the number of links from PubMed to SpringerLink full-texts; this tool helps to increase the visibility and content's dissemination of our journal. Comparing the data related to the period JanuaryAugust, PubMed linkouts increased by $46 \%$ from 2008 to 2009.

During 2009 we received about 250 submissions which is a good result for a relatively new journal.

Thomson Reuters-ISI will assign a 2009 Impact Factor. Unfortunately, a technical problem due to a late official communication, did not allow us to receive an Impact factor already in 2008. We will receive the official 2009 communication next summer. This will represent an important starting point for planning future development of the journal.

A new section edited by Peter Rosen and named Medical Illustration, started in the second half of 2009. It gathered the interest of the readers and several papers have already been received over the last months, carefully selected by the Co-Editor.

I wish to remind you to consult author instructions which have been changed over 2009 and to prepare manuscripts strictly following the instructions on the journal website (http://www.springer.com/medicine/internal/ journal/11739).

Please note that review articles are usually prepared by invited experts but also unsolicited high quality Reviews can be considered for publication. The journal accepts 
original studies but discourages case reports, except for very special ones. On the contrary, comments on published articles are welcome in the letter to the Editor section.

Finally, starting with the present issue a series of reviews will be published on peculiar aspects of venous thromboembolism, with particular remark to venous thrombosis in unusual sites. These reviews have been prepared by some of the major experts in this field. Again, your comments on this series are welcome.

I am sure you will join me in the work to make IEM a great journal. 